\title{
Polyclonal B Cell Activation in Lupus-prone Mice Precedes and Predicts the Development of Autoimmune Disease
}

\author{
Dennis M. Klinman \\ Laboratory of Retrovirus Research, Division of Virology, Center for Biologics Evaluation and Research, \\ Food and Drug Administration, Bethesda, Maryland 20892
}

\begin{abstract}
Polyclonal B cell activation is an early feature of autoimmune disease in humans and mice with systemic lupus erythematosus. The contribution of polyclonal activation to the progression of autoimmunity is unclear, however, since it precedes the development of end-organ damage by months or years. To examine this issue, 109 autoimmune-prone $(\mathrm{NZB} \times \mathrm{NZW}) \mathrm{F}_{1}$ $\times$ NZB backcross mice were hemi-splenectomized at 10 wk and the number and antigenic specificity of their Ig-secreting $B$ cells quantitated by ELISA spot assay. Of the 61 mice that had polyclonally increased numbers of Ig-secreting cells/spleen, 31 died by 6 mo. In contrast, $0 / 48$ backcross mice with normal numbers of Ig-secreting $B$ cells at 10 wk died over the same period $(P<0.001)$. Polyclonally activated mice also developed proteinuria earlier and more frequently than littermates with normal numbers of Ig-secreting cells $(P<0.001)$.

As adults, backcross mice with proteinuria expressed repertoires skewed towards the production of anti-DNA antibodies. At 10 wk these same mice expressed repertoires marked by polyclonal activation rather than preferential anti-DNA production. These findings indicate that autoimmune disease in SLE is accompanied by the autoantigen-driven production of autoantibodies but is preceded and predicted by polyclonal B cell activation. (J. Clin. Invest. 1990. 86:1249-1254.) Key words: autoimmunity • autoantibodies • polyclonal activation • lupus
\end{abstract}

\section{Introduction}

$(\mathrm{NZB} \times \mathrm{NZW}) \mathrm{F}_{1}$ mice spontaneously develop an autoimmune syndrome that resembles human systemic lupus erythematosus (SLE). Their disease is characterized by the production of IgG autoantibodies reactive with a variety of self antigens at 5-9 mo followed by immune complex-mediated glomerulonephritis and death (1-7). NZB mice develop an autoimmune disease which features hemolytic anemia and the increased production of $\operatorname{IgM}$ autoantibodies $(8,9)$. NZW mice are less autoimmune-prone but contribute genes critical to the development of lupus nephritis in $(\mathrm{NZB} \times \mathrm{NZW}) \mathrm{F}_{1}$ animals $(10,11)$.

Two processes, polyclonal B cell activation and autoantigen-driven immune stimulation, are thought to contribute to the production of autoantibodies in SLE (12-16). There is considerable uncertainty, however, concerning the relative importance of these two processes to disease pathogenesis. A

Address reprint requests to Dr. Dennis Klinman, Bldg. 29A, Rm. 3 D 16, Division of Virology, CBER, FDA, Bethesda, MD 20892.

Received for publication 9 January 1990 and in revised form 24 April 1990.

The Journal of Clinical Investigation, Inc.

Volume 86, October 1990, 1249-1254 role for autoantigen in the perpetuation of autoimmunity is supported by evidence showing that $(a)$ heightened responses to specific autoantigens are pathognomonic of active disease (such as the anti-DNA response in $(\mathrm{NZB} \times \mathrm{NZW}) \mathrm{F}_{1}$ mice and humans with lupus $[4,7,17,18]) ;(b)$ certain autoantigens are able to induce immune responses against themselves (19-21); (c) autoantibody-secreting B cells switch from IgM to IgG production over the course of disease $(18,20) ;(d)$ autoantibody affinity increases over time in a pattern reminiscent of conventional antigen-driven immune responses $(4,5)$; and $(e)$ autoantibody-secreting lymphocytes express clonally related $\mathrm{IgVh}$ region genes, consistent with a process of antigen-driven $B$ cell selection and expansion $(14,22)$. Yet there is also evidence which links the development of polyclonal $B$ cell activation with lupus. For example, the number of $B$ cells secreting non-autoantibodies as well as autoantibodies is significantly increased in mice and humans with SLE as is the responsiveness of lupus B cells to activation by $\mathrm{T}$ cell-derived lymphokines (13, 23-29).

It has been difficult to assess the contribution of polyclonal activation to the pathogenesis of SLE due to the confounding influence of autoantigen-specific immune stimulation. In all autoimmune strains studied to date, both of these processes have been detected $(13,21,23)$, making it impossible to independently assess the contribution of polyclonal activation to disease progression. The present study was designed to circumvent this problem by studying $(\mathrm{NZB} \times \mathrm{NZW}) \mathrm{F}_{1} \times \mathrm{NZB}$ backcross mice. These backcross mice inherit a complex assortment of autoimmunity associated genes (approximately six from the NZB parent $[6,10,11,30-32]$ and at least two of NZW origin $[10,11])$ and as a result show considerable variation in their autoimmune phenotype including a dissociation between polyclonal activation and autoantigen-specific stimulation $(10,11,33-35)$.

In this report, the presence of polyclonal activation and autoantigen-specific immune stimulation were monitored as a function of disease progression in 109 backcross mice using a sensitive and specific ELISA spot assay $(13,36,37)$. Results indicate that polyclonal B cell activation precedes and predicts the development of immune-mediated glomerulonephritis. In older mice, active renal disease was associated with the preferential production of anti-DNA (but not anti-ovalbumin) antibodies. However in younger mice, increased anti-DNA production did not correlate with subsequent disease progression. These findings are consistent with a model in which autoantibody production in lupus is initiated by polyclonal activation and perpetuated by autoantigen-specific stimulation $(21,38)$.

\section{Methods}

Animals. DBA/2, NZB, NZW, and $(\mathrm{NZB} \times \mathrm{NZW}) \mathrm{F}_{1}$ (sometimes referred to as $F_{1}$ ) mice were obtained from Jackson Laboratory, Bar Harbor, ME. $(N Z B \times N Z W) F_{1} \times N Z B$ backcross mice were bred and raised in our animal colony. All animals used in this work were female. 


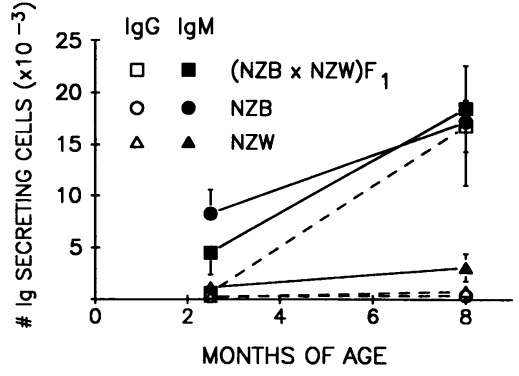

In some experiments, 10 -wk-old mice were hemi-splenectomized under general anesthesia using sterile technique as previously described (39). $6 \%$ of these animals died within $7 \mathrm{~d}$ of surgery and were discounted from all subsequent analyses. In other experiments, mice were killed by cervical dislocation and their spleens removed aseptically. Single cell suspensions were made from splenic lymphocytes in medium consisting of RPMI 1640 supplemented with $2 \%$ FCS as previously described (13). Mice were monitored for the appearance of protein in their urine (as a measure of renal inflammation) using albustix (Ames Division, Miles Laboratories Inc., Elkhart, IN) since this has been shown to be a sensitive indicator of the severity of glomerulonephritis (17).

ELISA-spot assays. Flat-bottom Immulon I microtiter plates (Dynatech Laboratories, Inc., Dynatech Corp., Alexandria, VA) were coated with soluble antigen (including ssDNA, histone [kind gift of Dr. Brian Kotzin, National Jewish Center for Immunology and Respiratory Medicine, Denver, CO]), TNP-KLH ${ }^{1}$ (keyhole limpet hemocyanin), ovalbumin, myosin, actin, and goat anti-mouse Ig $(13,40)$ or glutaraldehyde-fixed bromelain-treated mouse red blood cells (41), and then blocked with $1 \%$ BSA in PBS as previously described (13). Serial dilutions of single cell suspensions, starting with $10^{6}$ cells/well, were incubated on antigen-coated plates for $7 \mathrm{~h}$ at $37^{\circ}$ in a $5 \% \mathrm{CO}_{2}$ in air incubator as previously described (42). The cells were washed away with PBS/0.05\% Tween 20 and the plates overlaid for $2 \mathrm{~h}$ with phosphatase-conjugated antibodies to mouse IgM or IgG (Southern Biotechnology, Inc., Birmingham, AL). The antibodies produced by individual $B$ cells which bound to the plate were visualized by addition of a 5-bromo-3-chloroindolyl phosphate solution (Sigma Chemical Co., St. Louis, MO) in a low-melt agarose kept at $50^{\circ}$. Phosphatase acts on this substrate to produce a blue spot that cannot diffuse through the agarose once it solidifies at room temperature (36). The dilution of cells producing 20-40 spots/well was used to determine the total number of antibody-specific B cells/sample. The presence of BSA in the FCS used to conduct these assays completely inhibited the binding of BSA-specific antibodies to BSA-blocked plates, giving the assay a zero background. The sensitivity and specificity of this assay has been documented in antigen inhibition tests and in studies involving antigen-specific hybridoma cell lines $(13,36,37)$.

\section{Results}

Maturation of the $(N Z B \times N Z W) F_{1} B$ cell repertoire. The number of splenic lymphocytes producing IgM and IgG antibodies in NZB, NZW, and $F_{1}$ mice was examined at $10 \mathrm{wk}$ and 8 mo of age. Autoimmune NZB and $F_{1}$ mice had 5-15-fold more IgM-secreting B cells than NZW mice at both time points (Fig. 1). By comparison, $F_{1}$ mice had normal numbers of IgG-secreting B cells at 10 wk but developed significantly increased numbers of IgG producers at $8 \mathrm{mo}$, unlike the parental strains.

1. Abbreviations used in this paper: $\mathrm{KLH}$, keyhole limpet hemocyanin; OVA, ovalbumin.

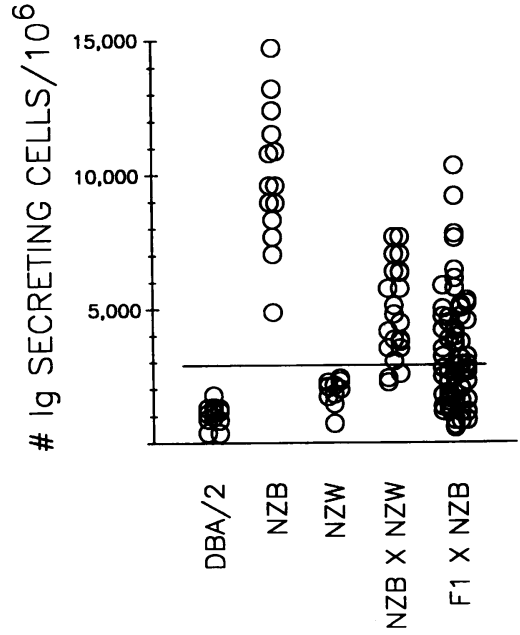

To examine whether polyclonal activation or autoantigenspecific immune stimulation was responsible for the increased frequency of Ig-secreting B cells in $F_{1}$ animals, the number of lymphocytes producing antibodies reactive with a panel of five autoantigens (ssDNA, histone, BrMRBC, myosin, and actin) and two conventional antigens (ovalbumin and TNP-KLH) was analyzed by ELISA spot assay. Polyclonal activation was considered to be present when the frequency of Ig-secreting B cells in a particular mouse exceeded the mean of NZW mice by $>2 \mathrm{SD}$. This cutoff was selected on the basis of previous work showing it provided a good separation between 10-wkold autoimmune and congenic non-autoimmune animals (21, 43). Results from studies of at least $12 \mathrm{mice} / \mathrm{strain}$ of each age indicate that $(a)$ all NZB, no NZW, and over $90 \%$ of $F_{1}$ mice were polyclonally activated at $10 \mathrm{wk}$ (Fig. 2$) ;(b)$ the number of $F_{1} B$ cells secreting antibodies reactive with each antigen in the panel increased $>14$-fold between $10 \mathrm{wk}$ and $8 \mathrm{mo}$, consistent with the effects of polyclonal activation (Fig. 3, top); and (c) reactivity against the autoantigens DNA and histone increased by 130 - and 240 -fold in these mice, consistent with specific immune responses against these autoantigens (Fig. 3, bottom).

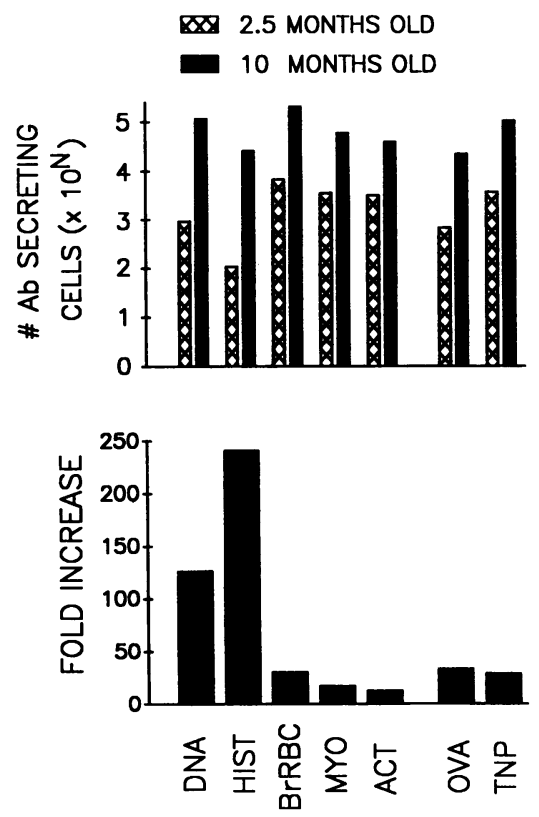

Figure 3. The total number of splenic $\left(\mathrm{NZB} \times \mathrm{NZW} \mathrm{F}_{1} \mathrm{~B}\right.$ cells secreting antibodies reactive with the autoantigens DNA, histone, bromelain-treated MRBC, myosin, and actin, and with the conventional antigens ovalbumin and TNP-KLH, was determined at 10 wk and 8 mo of age (top). The increase in antibody-secreting cell number over this period is shown in the lower panel. Note the disproportionately increased response to DNA and histone. Results represent the average of 12 mice/group. 


\section{(NZB X NZW)F1 X NZB MICE}

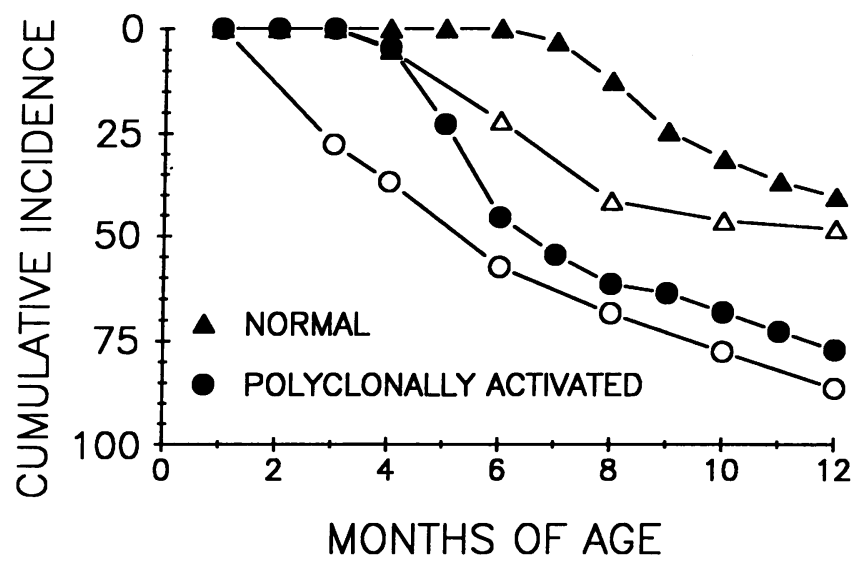

Figure 4. The cumulative incidence of $>2+$ proteinuria (open symbols) and death (closed symbols) in (NZB $\times N Z W) F_{1} \times$ NZB mice with or without polyclonal activation at $10 \mathrm{wk}$ is shown.

Polyclonal activation predicts the development of autoimmune disease in $F_{1} \times N Z B$ mice. A majority of adult $F_{1}$ mice develop an autoimmune-mediated glomerulonephritis that has been linked to the production of IgG autoantibodies reactive with DNA $(7,18)$. Some $F_{1} \times$ NZB backcross mice also develop renal disease although at a lower frequency than among $F_{1}$ 's $(11,35)$. A detailed analysis of $B$ cell activation and disease progression was undertaken in backcross animals to identify the factor(s) associated with disease progression. A cohort of $109 F_{1} \times$ NZB female mice were hemi-splenectomized at $10 \mathrm{wk}$ and examined by ELISA spot assay for $(a)$ the presence of polyclonal B cell activation; $(b)$ the presence of autoantigen-specific immune responses; and $(c)$ the relation of $(a)$ and $(b)$ to the subsequent development of glomerulonephritis and death.

Backcross mice were considered to be polyclonally activated if the frequency of B cells secreting Ig in their spleens exceeded by $>2$ SD the mean frequency of Ig-secreting B cells in NZW mice of the same age. Using this definition, polyclonal activation was detected in $56 \%$ of 10 -wk-old $F_{1} \times$ NZB animals (Fig. 2). IgM rather than IgG was secreted by $93-98 \%$ of the activated B cells in mice of this age (data not shown).

In the group of animals with normal numbers of Ig-secreting B cells, $63 \%$ survived until 12 mo and none died from autoimmune disease within the first 6 mo of life (Fig. 4). In contrast, nearly half of the mice with polyclonal activation died within 6 mo $(P<0.001$, Chi squared analysis) and only $23 \%$ survived for $1 \mathrm{yr}(P<0.01)$. Mice with polyclonal activation also developed proteinuria more frequently and at an earlier age than littermates with normal numbers of Ig-secreting B cells $(P<0.001$, Fig. 4).

Anti-DNA and anti-ovalbumin production in 10-wk-old $F_{1}$ $\times N Z B$ mice. 10-wk-old backcross mice with significantly increased numbers of Ig-secreting B cells had more lymphocytes producing antibodies against DNA and ovalbumin than did littermate controls (data not shown). To assess whether this resulted from polyclonal activation or autoantigen-specific stimulation, the frequency of $B$ cells reactive with each antigen was calculated as a percentage of the total number of Ig-secreting lymphocytes per mouse. This calculation compensated for differences in the number of Ig-secreting B cells present in normal versus polyclonally activated animals (13) and revealed that there was no significant difference between the $B$ cell repertoires expressed by polyclonally activated mice versus littermate controls (data not shown). The development of glomerulonephritis in backcross mice was then analyzed as a function of both total and antigen-specific production of IgM or IgG. Polyclonal activation at 10 wk correlated significantly $\left(R^{2}=0.78, P<0.01\right)$ with the development of glomerulonephritis whereas anti-DNA and anti-OVA production did not (Table I).

Increased anti-DNA production in mice with proteinuria. The B cell repertoires expressed by backcross mice that survived until 12 mo were also examined. Nearly $90 \%$ of these animals had significantly increased numbers of Ig-secreting splenic B cells when compared to NZW mice of the same age (Fig. 5, and data not shown). Less than $25 \%$ of these animals had been polyclonally activated at $10 \mathrm{wk}$, suggesting that the onset of B cell activation was delayed in a large proportion of backcross mice. The presence of polyclonal activation at 12 mo did not distinguish between mice with and without glomerulonephritis (Fig. 5). In contrast, mice with proteinuria had disproportionately increased numbers of B cells secreting IgM and IgG antibodies reactive with DNA (but not ovalbumin) when compared with nonproteinuric mice (Fig. 5).

The repertoires which had been expressed by these two groups at $10 \mathrm{wk}$ were then compared. Mice with proteinuria as adults had normal anti-DNA repertoires but more than twice as many Ig-secreting B cells at 10 wk than did littermates that did not develop proteinuria (Fig. 6).

\section{Discussion}

Results from this work indicate that polyclonal B cell activation precedes and predicts the development of glomerulonephritis and premature death in lupus-prone $\left(\mathrm{NZB} \times \mathrm{NZW} \mathrm{F}_{1}\right.$ $\times$ NZB mice. At 10 wk approximately one-half of backcross mice had significantly elevated numbers of Ig-secreting splenic

Table I. Correlation between the Frequency of Ig-secreting B Cells at $10 \mathrm{Wk}$ of Age and Disease Progression*

\begin{tabular}{lcc}
\hline \multicolumn{1}{c}{ Measure } & $\begin{array}{c}\mathrm{R}^{2} \text { as a function } \\
\text { of total cell No. }\end{array}$ & $\begin{array}{c}\mathrm{R}^{2} \text { as a function of } \% \\
\text { expressed reportoire }\end{array}$ \\
\hline Total Ig & $0.78^{\| \prime}$ & NA \\
Total IgM & $0.72^{\| 1}$ & NA \\
Total IgG & 0.24 & NA \\
Total anti-DNA & 0.46 & 0.02 \\
IgM anti-DNA & 0.38 & 0.05 \\
IgG anti-DNA & 0.27 & 0.10 \\
Total anti-OVA & 0.13 & 0.07 \\
IgM anti-OVA & 0.17 & 0.23 \\
IgG anti-OVA & 0.16 & 0.32 \\
\hline
\end{tabular}

The total number of lymphocytes $/ 10^{6}$ spleen cells secreting Ig or IgM at 10 wk of age correlated significantly (", $P<0.001$ ) with the development of autoimmune disease in $F_{1} \times$ NZB mice whereas the number of anti-DNA or anti-ovalbumin (anti-OVA) secreting cells $/ 10^{6}$ splenic lymphocytes ${ }^{\ddagger}$ or proportion of such cells when calculated as a percentage of the expressed repertoire ${ }^{\S}$ did not.

* The age at which mice developed $>2+$ proteinuria was used as the measure of disease progression. Linear regression analyses were performed using Lotus 123 on data from 109 mice studied over a one year period. NA, not applicable. 


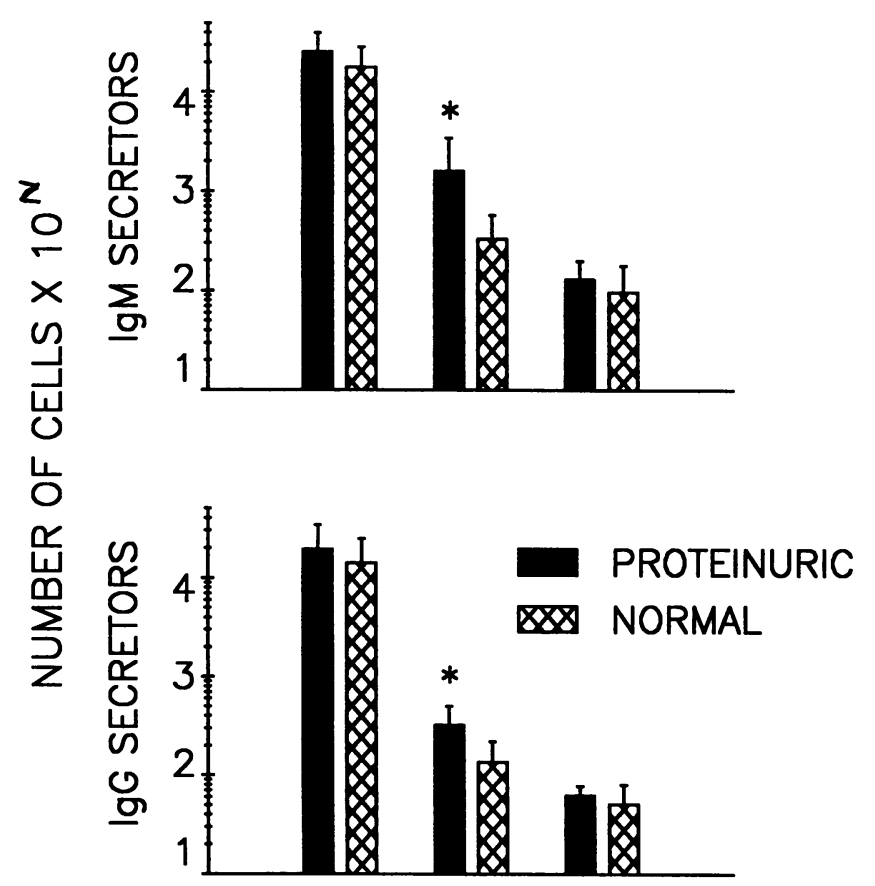

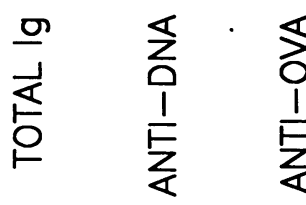

Figure 5. The number of Ig-secreting B cells $/ 10^{6}$ splenic lymphocytes in 12-mo-old $F_{1} \times$ NZB mice was determined. Results reflect the average and standard deviation of ten mice/group. Note that mice with $>2+$ proteinuria had significantly increased numbers of antiDNA-secreting lymphocytes.

B cells. $50 \%$ of these polyclonally activated animals were dead by 6 mo and nearly $90 \%$ had developed proteinuria by 12 mo. In contrast, 0 of 48 animals without polyclonal activation died of lupus by $6 \mathrm{mo}$ and less than half developed proteinuria by 1 yr. There was a strong correlation between the percentage of splenic B cells secreting Ig at 10 wk and the subsequent development of proteinuria or death $(P<0.001)$. These findings support the hypothesis that polyclonal activation contributes to the pathogenesis of systemic lupus erythematosus.

Other laboratories have demonstrated that the appearance of IgG anti-DNA antibodies coincides with the development of immune-complex mediated renal disease in NZB/W mice $(7,18)$. Consistent with these findings, we observed that glomerulonephritis in adult $F_{1}$ and backcross mice was associated with a preferential increase in anti-DNA secreting B cells (Fig. 5). NZB/W mice have also been shown to have disproportionately heightened responses to histone, retroviral GP 70, and T cells surface antigens $(10,34,35)$. This set of findings suggests that multiple (auto)antigens may contribute to the autoantibody production characteristic of murine lupus. However, the observation that anti-DNA production in 10-wk-old backcross mice does not correlate with disease progression (Fig. 6) suggests that this autoantigen-dependent immune stimulation occurs primarily during the latter stages of disease.

In this study, B cell activation in backcross mice was monitored by ELISA spot analysis of Ig-secreting lymphocytes in 10-wk and 12-mo-old animals. This required that young animals be hemi-splenectomized to obtain enough tissue to quantitate the number of B cells actively secreting Ig. A fragment of spleen was left in vivo to maintain the functional integrity of the animal's immune system (39). While this approach was technically more difficult than conventional studies of serum Ig levels, it provided data on the state of B cell activation unobtainable by conventional serum studies. As we and others have shown $(a)$ ELISA spot assays are $\sim 20$ times more sensitive than serum ELISA assays $(13,36,37)$, and $(b)$ the concentration of Ig in serum does not reflect the rate of Ig production or B cell stimulation alone but rather the balance between production and degradation. Since the rate of Ig catabolism increases as serum Ig levels rise (44), the effect of polyclonal activation on antibody production can be underestimated in studies of serum Ig levels, a problem which is resolved by using the ELISA spot assay to measure B cell activation directly.

Many laboratories have provided evidence that polyclonal activation contributes to autoantibody production in lupusprone mice $(12,13,15,23)$. The present report is the first to link the presence of such activation to the progression of autoimmune disease. Yet polyclonal activation was not invari-

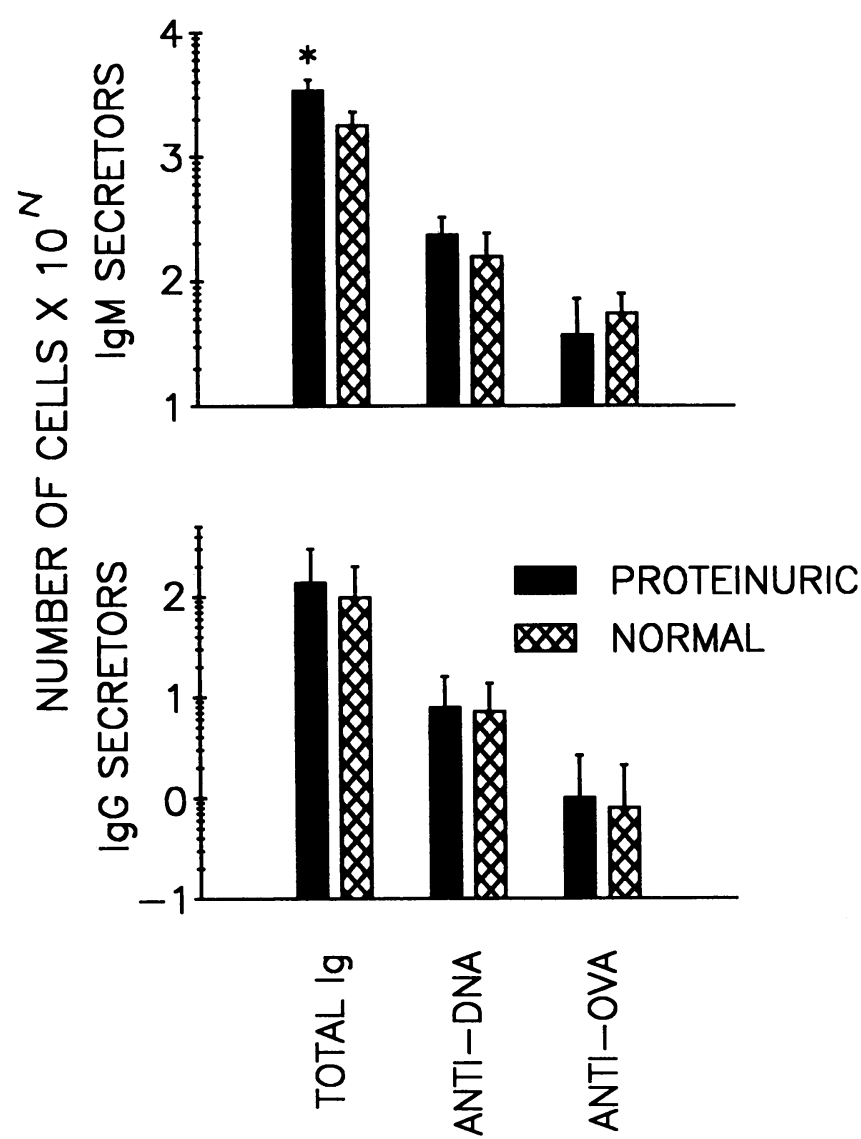

Figure 6. Results from repertoire studies performed at $10 \mathrm{wk}$ of age on the animals studied in Fig. 5 are presented. Mice that as adults had $>2+$ proteinuria and increased anti-DNA antibody production did not express repertoires skewed towards the production of antiDNA antibodies at $10 \mathrm{wk}$. They did, however, have significantly increased numbers of IgM-secreting B cells when compared with littermates which had normal renal function as adults. 
ably associated with the development of active lupus. Approximately $10 \%$ of those backcross mice with increased numbers of Ig-secreting B cells at $10 \mathrm{wk}$ did not develop proteinuria over the subsequent 10 mo. Nor were all mice that developed glomerulonephritis polyclonally activated at $10 \mathrm{wk}$. One interpretation of the latter finding is that polyclonal activation is not a necessary precursor to disease. Alternatively, polyclonal activation may have developed in proteinuric mice between the age when they were tested for polyclonal activation (10 wk) and the onset of their disease (4-10 mo later). This interpretation is supported by the finding that nearly $90 \%$ of backcross mice had significantly increased numbers of activated B cells by 12 mo although less than a quarter of these animals had been polyclonally activated 10 mo earlier. Future studies comparing the time of onset of polyclonal activation with the development of glomerulonephritis in backcross mice may help resolve this issue.

An additional source of variability in these experiments was that introduced by the ELISA spot assay. In preliminary experiments, donor spleens were divided into four fragments. Variation as high as $10 \%$ was found in the number of Ig-secreting $B$ cells $/ 10^{6}$ lymphocytes detected in different fragments from the same spleen. This variation might be due to microheterogeneity in the distribution of activated splenic B cells and/or technical variability in the ELISA spot assay. At a maximum, such variability could have changed the assignment of up to $14 \%$ of the animals examined in this report to the polyclonally activated or normal groups. The actual number of animals assigned incorrectly is probably much lower, since $(a)$ experimental variability was frequently less than $10 \%$, and $(b)$ any error in quantitating the number of Ig-secreting B cells would be equally likely to place an animal more firmly in the correct category rather than to change its category. When the data were reexamined to exclude mice with intermediate numbers of Ig-secreting B cells (which might have been incorrectly assigned) the correlation between polyclonal activation and disease progression persisted. For example, the group of mice with the highest $25 \%$ of Ig-secreting cells/spleen had a mortality rate of $87 \%$ by 12 mo whereas the group of mice with the lowest $25 \%$ of Ig-secreting cells had a mortality rate of under $35 \%(P<0.01)$.

Previous studies have shown that at least two independently segregating loci in NZW mice (one of which is associated with the MHC locus) and at least six genetic loci in NZB mice influence autoantibody production and/or disease $(2,10$, $30,31,33-35,45-46)$. Analyses of multiple autoimmune, normal, and recombinant inbred mouse strains have demonstrated further that the trait of polyclonal activation breeds true $(13,23)$. The autoimmune phenotypes expressed by backcross mice may therefore reflect a complex interaction between multiple autoimmunity-associated genes. For example, while all NZB mice and no NZB mice developed polyclonal activation by $10 \mathrm{wk}, 90 \%$ of $F_{1}$ animals (which are heterozygous at all loci) and just over half of backcross mice (which inherit a mixture of homozygous NZB and heterozygous NZB/NZW genes) expressed significantly increased numbers of Ig-secreting B cells at that age. Additional backcross mice developed polyclonal activation as they grew older, so that by 12 mo nearly $90 \%$ of all animals had increased numbers of Ig-secreting B cells. Such complexity in the expression of a trait is not easily attributed to a single gene. Similar complexity is seen in the development of IgG hypergammaglobulinemia and glomerulonephritis. These traits are absent from most NZB and NZW parental mice, present in most $F_{1}$ 's, but show considerable variability in age of onset and severity in backcross animals $(2,11,33)$.

We recently postulated that murine lupus develops in two phases, the first being characterized by polyclonal B cell activation and the second by the (auto)antigen-driven expansion of autoreactive B cells $(13,21,38)$. Results from this and other laboratories indicate that the autoantigen-specific phase of SLE serves to magnify and perpetuate the production of pathogenic autoantibodies (such as those against DNA in (NZB $\times \mathrm{NZW}) \mathrm{F}_{1}$ mice and against $\mathrm{Sm}$ in MRL-lpr/lpr mice $(4,7$, $19,21)$ ). Findings in the present report emphasize the correlation which exists between polyclonal activation and the development of active disease. In this context, polyclonal activation might serve to $(a)$ initiate the production of those autoantibodies that cause tissue damage and the release of autoantigens; $(b)$ increase the pool of self-reactive B cells available for later autoantigen-specific stimulation; $(c)$ interfere with the development of self tolerance by stimulating B cells that would otherwise be deleted; or $(d)$ disrupt the regulatory environment required for normal immune function (for example by interfering with the development of Id-anti-Id networks). These observations invite further study into the possibility that therapy during the early polyclonal phase of human and murine lupus might prevent or delay disease progression.

\section{Acknowledgments}

I would like to thank Drs. Alfred Steinberg, Arthur Krieg, and Brian Kotzin for their critical review of this manuscript.

\section{References}

1. Howie, J. B., and B. J. Helyer. 1968. The immunology and pathology of NZB mice. Adv. Immunol. 9:512-525.

2. Bocchieri, M. H., A. Cooke, J. B. Smith, M. Weigert, and R. J. Riblet. 1982. Independent segregation of NZB immune abnormalities in NZB X C58 recombinant inbred mice. Eur. J. Immunol. 12:349354.

3. Lambert, P. H., and F. J. Dixon. 1968. Pathogenesis of the glomerulonephritis of NZB/W mice. J. Exp. Med. 127:507-513.

4. Papoian, R., R. Pillarisetty, and N. Talal. 1977. Immunological regulation of spontaneous antibodies to DNA and RNA. II. Sequential switch from IgM to IgG in NZB/BZW F1 mice. Immunology. 32:7579.

5. Steward, M. W., and F. C. Hay. 1976. Changes in immunoglobulin class and subclass of anti-DNA antibodies to DNA and RNA. II. Sequential switch from IgM to IgG in NZB/W F1 mice. Clin. Exp. Immunol. 26:363-370.

6. Kohno, A., H. Yoshida, K. Sekita, N. Maruyama, S. Ozaki, S. Hirose, and T. Shirai. 1984. Genetic regulation of the class conversion of dsDNA-specific antibodies in (NZB $\times$ NZW)F1 hybrids. Immunogenetics. 18:513-524.

7. Ebling, F., and B. H. Hahn. 1980. Restricted subpopulations of DNA antibodies in kidneys of mice with systemic lupus. Arthritis Rheum. 23:392-398.

8. Bielschowsky, M., B. J. Helyer, and J. B. Howie. 1959. Spontaneous anemia in mice of the NZB/BL strain. Proc. Univ. Otago Med. Sch. 37:9-25.

9. Jyonouchi, H. P., W. Kincade, R. A. Good, and M. E. Gershwin. 1983. B lymphocyte lineage cells in newborn and very young NZB 
mice: evidence for regulatory disorders affecting B cell formation. $J$. Immunol. 131:2219-2225.

10. Kotzin, B. L., and E. Palmer. 1987. The contribution of NZW genes to lupus-like disease in $(\mathrm{NZB} \times \mathrm{NZW}) \mathrm{F} 1$ mice. $J$. Exp. Med. 165:1237-1251.

11. Knight, J. G., and D. D. Adams. 1978. Three genes for lupus nephritis in NZB $\times$ NZW mice. J. Exp. Med. 147:1653-1660.

12. Izui, S. P., P. J. McConahey, and F. J. Dixon. 1978. Increased spontaneous polyclonal activation of B lymphocytes in mice with spontaneous autoimmune disease. J. Immunol. 121:2213-2219.

13. Klinman, D. M., and A. D. Steinberg. 1987. Systemic autoimmune disease arises from polyclonal B cell activation. J. Exp. Med. 165:1755-1760.

14. Shlomchik, M., A. Marshak-Rothstein, C. B. Wolfowicz, T. L. Rothstein, and M. G. Weigert. 1987. The role of clonal selection and somatic mutation in autoimmunity. Nature (Lond.). 328:805-811.

15. Theofilopoulos, A. N., and F. J. Dixon. 1981. Etiopathogenesis of murine systemic lupus erythematosus. Immunol. Rev. 55:179-216.

16. Casali, P., and A. L. Notkins. 1989. CD5+ B lymphocytes, polyreactive antibodies and the human B cell repertoire. Immunol. Today. 10:364-368.

17. Schur, P. H., and J. Sandson. 1968. Immunological factors and clinical activity in SLE. $N$. Engl. J. Med. 278:533-540.

18. Datta, S. K., H. Patel, and D. Berry. 1987. Induction of a cationic shift in IgG anti-DNA autoantibody. J. Exp. Med. 165:12521268.

19. Eisenberg, R. A., J. B. Winfield, and P. L. Cohen. 1982. Subclass restriction of anti-Sm antibody in MRL mice. J. Immunol. 129:2146-2149.

20. Eisenberg, R. A., S. Y. Craven, and P. L. Cohen. 1987. Isotype progression and clonality of anti-Sm autoantibodies in MRL/Mp-lpr/ lpr mice. J. Immunol. 139:728-733.

21. Klinman, D. M., R. A. Eisenberg, and A. D. Steinberg. 1990. Development of the autoimmune B cell repertoire in MRL-lpr/lpr mice. J. Immunol. 144:506-512.

22. Shlomchik, M., D. Nemazee, J. Van Snick, and M. Weigert. 1987. Variable region sequences of murine IgM anti-IgG monoclonal autoantibodies (Rheumatoid factors). J. Exp. Med. 165:970-987.

23. Ishigatsubo, Y., A. D. Steinberg, and D. M. Klinman. 1988. Genes which induce systemic autoimmunity also induce polyclonal B cell activation. Eur. J. Immunol. 18:1089-1094.

24. Budman, D. R., E. B. Merchant, A. D. Steinberg, B. Doft, M. E. Gershwin, E. Lizzio, and J. P. Reeves. 1977. Increased spontaneous activity of antibody-forming cells in the peripheral blood of patients with active SLE. Arthritis Rheum. 20:829-833.

25. Blaese, R. M., J. Grayson, and A. D. Steinberg. 1980. Elevated immunoglobulin secreting cells in the blood of patients with active systemic lupus erythematosus: correlation of laboratory and clinical assessment of disease activity. Am. J. Med. 69:345-350.

26. Feldman, M. D., D. P. Huston, J. Karsh, J. E. Balow, and A. D. Steinberg. 1982. Correlation of serum IgG, IgM and anti-native DNA antibodies with renal and clinical indices of activity in SLE. J. Rheumatol. 9:52-58.

27. Ueda, Y., T. Sakane, and T. Tsunematsu. 1989. Hyperreactivity of activated B cells to $B$ cells growth factors in patients with systemic lupus erythematosus. J. Immunol. 143:3988-3993.

28. Umland, S. P., N. F. Go, J. E. Cupp, and M. Howard. 1989. Responses of B cells from autoimmune mice to IL-5. J. Immunol. 142:1528-1535.
29. Herron, L. R., R. L. Coffman, M. W. Bond, and B. L. Kotzin. 1988. Increased autoantibody production by NZB/NZW B cells in response to IL-5. J. Immunol. 141:842-848.

30. Raveche, E. S., A. D. Steinberg, L. W. Klassen, and J. H. Tjio. 1978. Genetic studies in NZB mice. I. Spontaneous autoantibody production. J. Exp. Med. 147:1487-1502.

31. Raveche, E. S., E. A. Novotny, C. T. Hansen, J. H. Tjio, and A. D. Steinberg. 1981. Genetic studies in NZB mice. V. Recombinant inbred lines demonstrate that separate genes control autoimmune phenotype. J. Exp. Med. 153:1187-1197.

32. Gioud, M., B. L. Kotzin, F. L. Rubin, F. G. Joslin, and E. M. Tan. 1983. In vivo and in vitro production of anti-histone antibodies in NZB/NZW mice. J. Immunol. 131:269-282.

33. Hirose, S., R. Nagasawa, I. Sekikawa, M. Hamaoki, Y. Ishida, H. Sato, and T. Shirai. 1983. Enhancing effect of H-2 linked NZW gene(s) on the autoimmune traits of (NZB $\times \mathrm{NZW)F1} \mathrm{mice.} \mathrm{J.} \mathrm{Exp.}$ Med. 158:228-233.

34. Maruyama, N., F. Furukawa, Y. Nakai, Y. Sasaki, K. Ohta, S Ozaki, S. Hirose, and T. Shirai. 1983. Genetic studies of autoimmunity in NZB mice. IV. J. Immunol. 130:740-746.

35. Yoshida, H., A. Kohno, K. Ohta, S. Hirose, N. Maruyama, and T. Shirai. 1981. Genetic studies of autoimmunity in New Zealand mice. III. J. Immunol. 127:433-437.

36. Sedgwick, J. D., and P. G. Holt. 1983. A solid phase immunoenzymatic technique for the enumeration of specific antibody secreting cells. J. Immunol. Methods. 57:301-309.

37. Ando, D. G., F. M. Ebling, and B. H. Hahn. 1986. Detection of native and denatured DNA antibody forming cells by the enzymelinked immunospot assay. A clinical study of $(\mathrm{NZW} \times \mathrm{NZW}) \mathrm{F} 1$ mice. Arthritis Rheum. 29:1139-1146.

38. Klinman, D. M., Y. Ishigatsubo, and A. D. Steinberg. 1988. Acquisition and maturation of expressed B cell repertoires in normal and autoimmune mice. J. Immunol. 141:801-806.

39. Raveche, E. S., O. Alabaster, J. H. Tjio, J. Taurog, and A. D. Steinberg. 1981. Analysis of NZB hyperdiploid spleen cells. J. Immunol. 126:154-160.

40. Monestier, M., A. Manheimer-Lory, B. Bellon, C. Painter, H. Dang, N. Talal, M. Zanetti, R. Schwartz, D. Pisetsky, R. Kuppers, et al. 1986. Shared idiotopes and restricted immunoglobulin variable region heavy chain genes characterize murine autoantibodies of various specificities. J. Clin. Invest. 78:753-759.

41. Klinman, D. M., and A. D. Steinberg. 1987. Novel ELISA spot assays to quantitate B cells specific for $\mathrm{T}$ cell and bromelated red blood cell autoantigens. J. Immunol. Methods. 102:157-164.

42. Klinman, D. M., and A. D. Steinberg. 1986. Proliferation of anti-DNA producing NZB B cells in a non-autoimmune environment. J. Immunol. 137:69-75.

43. Klinman, D. M. 1989. Regulation of B cell activation in autoimmune mice. Clin. Immunol. Immunopathol. 53:S25-S34.

44. Steinberg, A. D., M. C. Gelfand, J. A. Hardin, and D. T. Lowenthal. 1975. Therapeutic studies in NZB/W mice. III. Relationship between renal status and efficacy of immunosuppressive drug therapy. Arthritis Rheum. 18:9-14.

45. Miller, M. L., E. S. Raveche, C. A. Laskin, D. M. Klinman, and A. D. Steinberg. 1984. Genetic studies in NZB mice. VI. Association of autoimmune traits in recombinant inbred lines. J. Immunol. 133:1325-1331.

46. Manny, N., S. D. Datta, and R. S. Schwartz. 1979. Synthesis of IgM by cells of NZB and SWR mice and their crosses. J. Immunol. 122:1220-1227. 